\title{
EFFECT OF Sn-Zr SUBSTITUTION ON STRUCTURAL AND MAGNETIC PROPERTIES OF CALCIUM NANOPARTICLES HEXAFERRITE PREPARED BY SOL-GEL AUTO COMBUSTION METHOD.
}

\author{
A.S.Kakde*, B.S.Satone”, K.G.Rewatkar*, P.S.Sawadh\$, M.S.Choukwse ${ }^{\circledR}$ \\ *Department of Physics, Dr .Ambedkar College, Deeksha Bhoomi, Nagpur \\ \# Department of Physics, Sindu Junior College, Nagpur. \\ \$Department of Physics, Bapurao Deshmukh College of Engg., \\ Sewagram, Wardha. \\ @Department of Applied Physics, Govt. Goa's Engineering College, Goa. \\ Corresponding Author: E-mail: anandkakde85@gmail.com
}

\begin{abstract}
A series of M-type hexagonal ferrite with composition $\mathrm{Ca}(\mathrm{SnZr})_{\mathrm{x}} \mathrm{Fe}_{12-2 \mathrm{x}} \mathrm{O}_{19}(\mathrm{x}=0.8,1.0)$ have been synthesized by sol-gel auto combustion technique. The precursor was annealed at temperatures $800^{\circ} \mathrm{C}$. The annealed powders were characterized using X-ray diffractometer (XRD), vibrating sample magnetometer (VSM), DC electrical resistivity and dielectric measurements. X-ray diffraction studies established the presence of a single phase with the theoretical space group $\mathrm{P} 63 / \mathrm{mmc}$ (194), and computed cell parameters of ' $a$ ' and 'c'. Sharp changes were observed in particle size (D) and lattice constant ('a' \& 'c') with the increasing Sn and Zr content. The VSM data revealed that, the saturation magnetization values show a decreasing behavior with increasing concentration of dopant due to the lower magnetic moment of $\mathrm{Sn}^{2+}(3 \mu \mathrm{B})$ as compared to $\mathrm{Fe}^{3+}(5 \mu \mathrm{B})$ and coercivity increases due to enhancement of magnetocrystalline anisotropy. The DC electrical resistivity $(\rho)$ was measured as a function of temperature from $303 \mathrm{~K}-623 \mathrm{~K}$. The DC electrical studies show that at room temperature these ferrites exhibit high resistivity which goes on decreasing as the dopant concentration increases. The effect of $\mathrm{Sn}^{+2}$ and $\mathrm{Zr}^{+4}$ substitutions on dielectric loss had been studied for synthesized ferrite in the frequency range from $10 \mathrm{KHz}$ to $1 \mathrm{MHz}$.
\end{abstract}

Keywords: Hexagonal ferrite, XRD, VSM, X-ray density, coercivity, magnetic moment etc.

\section{Introduction}

Calcium ferrite having general formula $\mathrm{CaFe}_{12} \mathrm{O}_{19}$ is a famous magnetic material which is one of the most important hard magnetic materials, 
widely used for permanent magnets, magnetic recording media and microwave absorbers [1-4]. It is well known that their structural and magnetic properties are closely connected to the distribution of Fe ions among various interstitial sites, and it has been found that these properties can be changed by doping of $\mathrm{Fe}^{3+}$ and $\mathrm{Ca}^{2+}$ with different types of cations and cation combinations. The M-type calcium ferrite crystallizes in an hexagonal structure with 64 ions per unit cell on 11 different symmetry sites. The $24 \mathrm{Fe}^{3+}$ atoms are distributed over five distinct sites: three octahedral sites $\left(12 \mathrm{k}, 2 \mathrm{a}\right.$ and $\left.4 \mathrm{f}_{2}\right)$, one tetrahedral $\left(4 \mathrm{f}_{1}\right)$ site and one bipyramidal site $(2 \mathrm{~b})$. The magnetic structure given by the Gorter model is ferromagnetic with five different sublattices, three parallel $(12 \mathrm{k}, 2 \mathrm{a}$ and $2 \mathrm{~b})$ and two antiparallel $\left(4 \mathrm{f}_{1}\right.$ and $\left.4 \mathrm{f}_{2}\right)$ which are coupled by super exchange interactions through $\mathrm{Fe}^{3+}-\mathrm{O}^{2-}-\mathrm{Fe}^{3+}$ ions. Calcium ferrite is a ferromagnetic material, which has a collinear fivesublattice magnetic structure and uniaxial magnetocrystalline anisotropy with easy axis parallel to the $c$ axis of the hexagonal unit cell. Its crystal structure can be divided in several blocks according to the stacking form of closely packed oxygen ions. The important applications are in materials quality, impurity levels and defect detection, band gap determination and recombination mechanism. The properties of the substituted hexaferrites are largely dependent on their characteristics such as anisotropy, crystallinity, particle size, and substitution rate. Many process routes have been devised for the preparation of hexaferrite powders with refined particle size, narrow particle-size distribution, minimal particle agglomeration, and high crystallinity, including the hydrothermal process, the microemulsion technique and the coprecipitation route [6-8]. In recent years, the sol-gel auto combustion process has been widely studied for the synthesis of ferrite powders [9, 10]. In this technique, a variety of reducing agents have been explored for the formation of homogenous, stable, and transparent sol-gel solutions, such as urea, citric acid, stearic acid and glycine. Among these 
processes, sol-gel methods are more popular for the preparation of hard ferrite nanomaterials.

\section{Experimental}

\subsection{Synthesis}

$\mathrm{Ca}(\mathrm{SnZr})_{x} \mathrm{Fe}_{12-x} \mathrm{O}_{19}(x=0.8 \& 1.0)$ were synthesized using the urea as fuel by sol-gel auto combustion method [11]. The AR grade calcium nitrate, iron nitrate, zirconyl nitrate, tin chloride and urea were weighed in appropriate stoichiometric proportions and dissolved in required amount of distilled water. Then, all the dissolved solutions were mixed with continued stirring and a homogenous mixture was obtained. The resulting solution was then heated at $60^{\circ} \mathrm{C}$ and stirred using a hot plate magnetic stirrer that resulted sol into gel formation. The formed gel then fired in specially designed microwave, where within few minutes of irradiation, gel started boiling and white fumes come out from the exhaust provided on the top of the oven. After few minutes gel gets burnt out and resulted into ash brown powder. The resultant ash powder was grinded for several hours in pestal mortal to obtaine finalized nanopowder of synthesized material. Further, the powder was calcinated at $800^{\circ} \mathrm{C}$ for $8 \mathrm{hrs}$ at the rate of $100^{\circ} \mathrm{C} / \mathrm{hr}$ and slowly cooled down to room temperature at the same rate to get desired samples.

\subsection{Physical measurements}

Powder X-ray diffraction (XRD) studies have been carried out using a Bruker Advance spectrophotometer with $\mathrm{Cu}-\mathrm{Ka}$ radiation $(\lambda=1.54 \AA)$. The lattice constants 'a'and 'c', x-ray density, porosity and physical structure were determined from XRD.

At the room temperature, various magnetic parameters such as saturation magnetization, coercivity, remanent magnetization etc. were measured with Lakeshore VSM 7410 with a maximum field of $1.5 \mathrm{KG}$. 
The DC electrical resistivity and dielectric loss of the samples in the form of pellets with silver coating for electrical contacts were carried out using Wayn Kerr Impendence Precision Analyzer 6500B.

\section{Result and Discussion}

\subsection{Structural Properties}

The powder X-Ray diffractographs for all the samples annealed at $800^{\circ} \mathrm{C}$ have been recorded and are shown in Figure 1. The XRD patterns of the ferrite samples show characteristic diffraction peaks corresponding to the M-type calcium ferrite structure, having point group $\mathrm{P} 63 / \mathrm{mmc}$, indicating that the crystal structure does not transform and remains hexagonal magnetoplumbite after substitution with $\mathrm{Sn}$ and $\mathrm{Zr}$ ions.
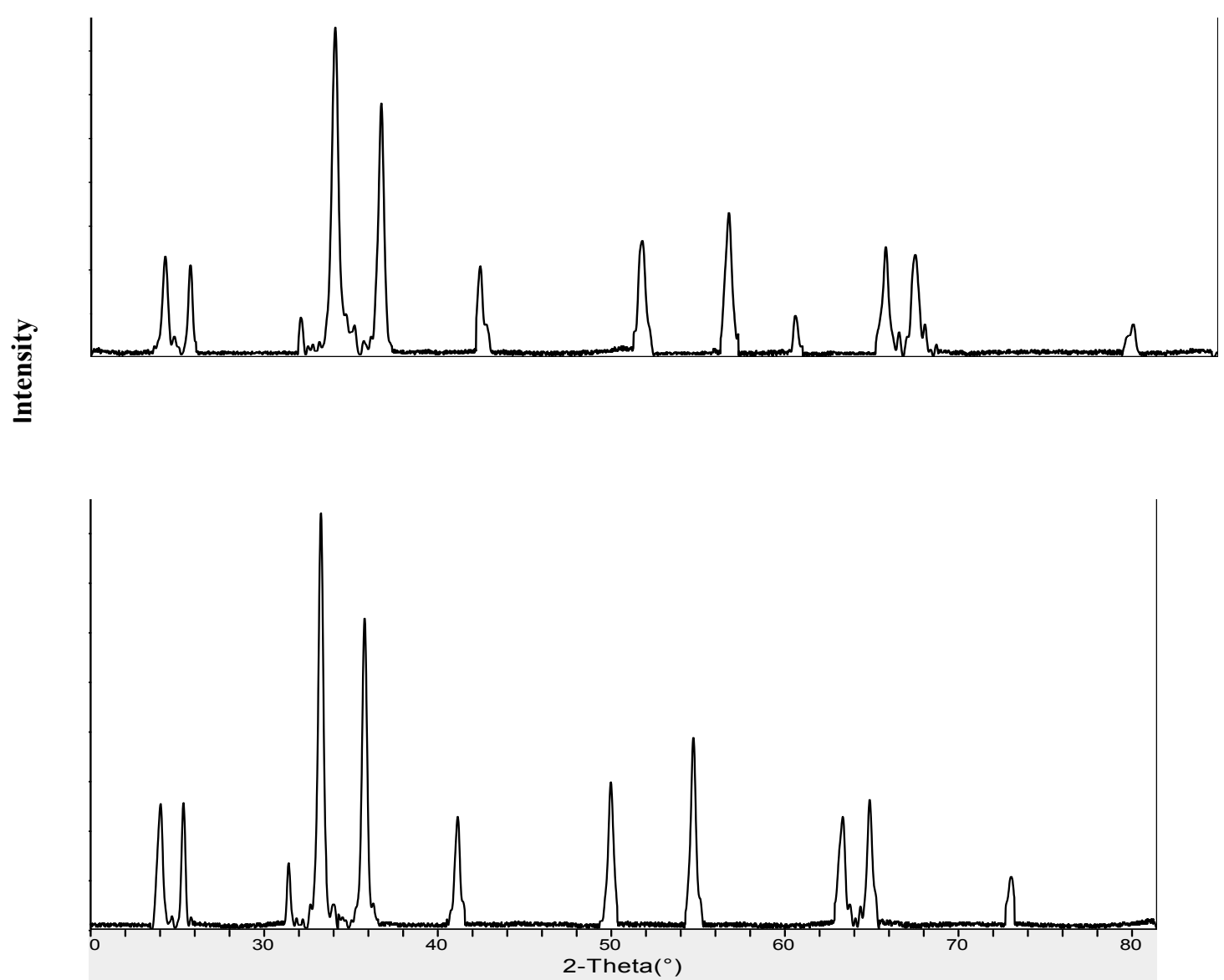

Figure 1: XRD Pattern of $\mathrm{Ca}(\mathrm{SnZr})_{x} \mathrm{Fe}_{12-x} \mathrm{O}_{19} ; \mathrm{x}=0.8,1.0$ annealed at $800^{\circ} \mathrm{C}$ 
The average crystallite size for each composition has been calculated from the line broadening of the most intense peak of magnetoplumbite structure according to Scherrer equation [12] given below $D=k \lambda / \beta \cos \theta$

Where, $D$ is the average size of the crystallites, $k$ is the scherrer constant, $\lambda$ is the wavelength of radiation (1.5405 $\AA$ ), $\beta$ is the peak width at half height or full width half maximum. The values of crystallite size are listed in Table $\mathbf{1}$ and the average crystallite size is found to $45.5 \mathrm{~nm}$.

Table 1:Lattice constants, Crystallite size, Magnetization saturation, Coericivity \& Squareness ratio of $\mathrm{Ca}(\mathrm{SnZr})_{x} \mathrm{Fe}_{12-x} \mathrm{O}_{19}$.

\begin{tabular}{|c|c|c|c|c|c|}
\hline $\begin{array}{c}\text { Ferrite composition } \\
\mathrm{Ca}(\mathrm{SnZr}){ }_{x} \mathrm{Fe}_{12-x} \mathrm{O}_{19}\end{array}$ & 'a' \& 'c' (̊) & $\mathrm{D}(\mathrm{nm})$ & $\begin{array}{l}\mathrm{Ms} \times 10^{-} \\
(\mathrm{emu} / \mathrm{g})\end{array}$ & $\mathrm{Hc}(\mathrm{G})$ & $\begin{array}{c}\text { Squareness } \\
\text { Ratio (Sq) }\end{array}$ \\
\hline$x=0.8$ & $\begin{array}{c}a=5.8494 \\
c=22.3019\end{array}$ & 44.08 & 15.3 & 526.57 & 0.049 \\
\hline$x=1.0$ & $\begin{array}{c}a=5.8524 \\
c=22.3200\end{array}$ & 47.10 & 12.92 & 598.37 & 0.057 \\
\hline
\end{tabular}

\subsection{Magnetic Properties}

The hysteresis curves at the room temperature shown in Fig.2 for samples sintered at $800^{\circ} \mathrm{C}$. From these plots, saturation magnetization (Ms), coercivity (Hc) and squareness ratio (Sq) have been calculated and are given in Table 1. From Table 1, it is seen that the saturation magnetization decreases as the $\mathrm{Sn}^{2+}$ concentration is increased. This is attributed to the lesser magnetic moment of $\mathrm{Sn}^{2+}$ ions $(3 \mu \mathrm{B})$ as compared to $\mathrm{Fe}^{3+}$ ions $(5 \mu \mathrm{B})$ and their substitution in $12 \mathrm{k}$ and $2 \mathrm{a}$ sites of the lattice, in preference to the $4 f_{2}$ sites. The coercivity value increases from 526.57 to $598.37 \mathrm{G}$ with increasing dopants concentration due to enhancement in magnetocrystalline anisotropy. 


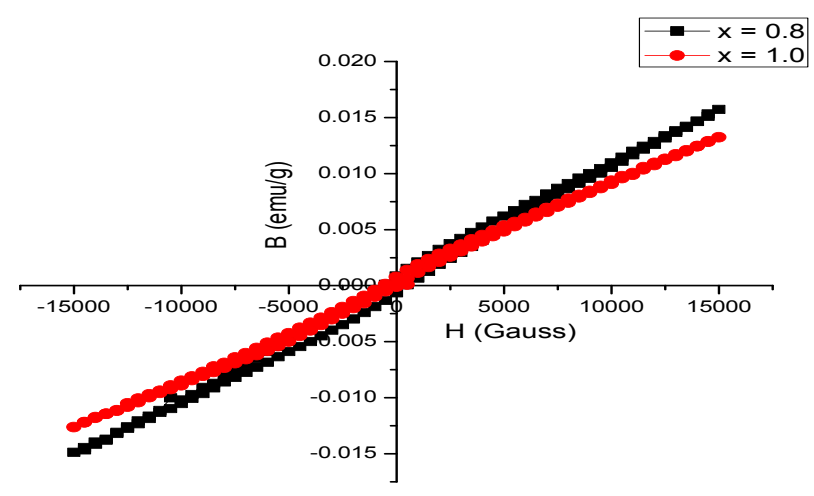

Figure 2: Magnetization plot for $\mathrm{Ca}(\mathrm{SnZr})_{x} \mathrm{Fe}_{12-x} \mathrm{O}_{19} ; \mathrm{x}=0.8,1.0$

annealed at $800^{\circ} \mathrm{C}$

The squareness ratio $S Q R$, for these samples is denoted by the ratio of $(\mathrm{Mr} / \mathrm{Ms})$.Where, $\mathrm{Mr}$ is the remnance and $\mathrm{Ms}$ is the saturation magnetisation. The values are essentially a measure of squareness of the hysteresis loop. The squareness (SQR) should be less than 0.5 for the single domain magnetic structure of the sample. In our case, all the sample have SQR is less than 0.5 which eventually confirms the single domain structure for the samples. From Table 1, it is observed that the squareness ratio increases with increase in $\mathrm{Sn}-\mathrm{Zr}$ ion concentration. Compared to this relatively low value, in general however, large SQRvalues are preferred in many applications such as recording media.

\subsection{DC electrical resistivity}

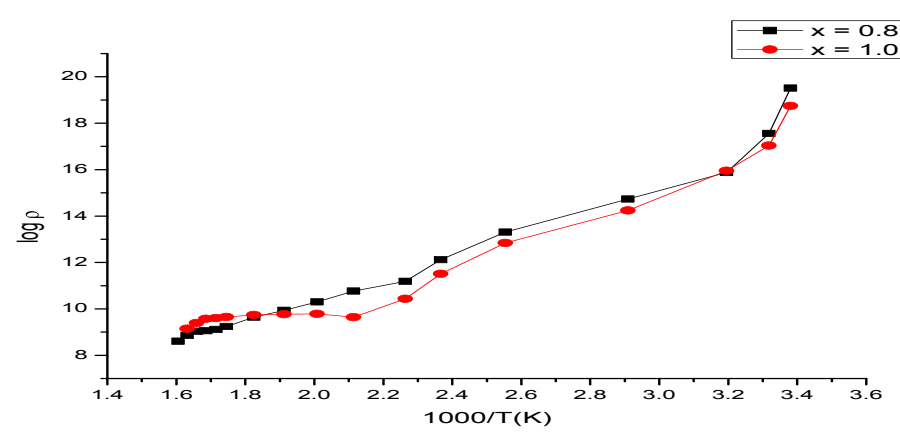

Figure2: Variation of $\log \rho$ with inverse temperature for $\mathrm{Ca}(\mathrm{SnZr}){ }_{x} \mathrm{Fe}_{12}$ ${ }_{x} \mathrm{O}_{19} ; \mathrm{x}=0.8,1.0$ 
The DC electrical resistivity of all the samples decreased with increasing temperature in accordance with Arrhenius equation [13].

$$
\rho=\rho_{\mathrm{o}} \exp \left(\Delta \mathrm{E} / \mathrm{k}_{\mathrm{B}} \mathrm{T}\right)
$$

Fig. 3 shows, by increasing the temperature, the conductivity of the synthesized ferrite increases that indicating these ferrites have semiconducting behavior [14]. At high temperature, the conduction in ferrite is due to polaron hopping [15]. The electrical conductivity in ferrites is mainly due to hopping of electrons between ions of the same element present in more than one oxidation state, distributed randomly over the crystallographic equivalent lattice sites. The structure of hexaferrite form hexagonal close packed oxygen lattice with cation at the one tetrahedral site (A), three octrahedral site (B) and one trigonal bipyramidal site $(\mathrm{C})$. The distance between two ferric ions at $\mathrm{B}$ sites is much smaller than the distance between two metals ions at $A$ and $B$ sites, therefore the hopping between the A-B sites has very less probability as compared with B-B sites hopping. The hopping between AA sites does not occur, as there are only $\mathrm{Fe}^{3+}$ ions at $\mathrm{A}$ sites and $\mathrm{Fe}^{2+}$ ions are formed during sintering process preferentially occupy B sites only [16].

\subsection{Dielectric Property}

Variation of dielectric constant with frequency is shown in Fig. 4. It is seen that the dielectric constant decreases rapidly with increasing frequency and reaches a constant value beyond certain frequency.

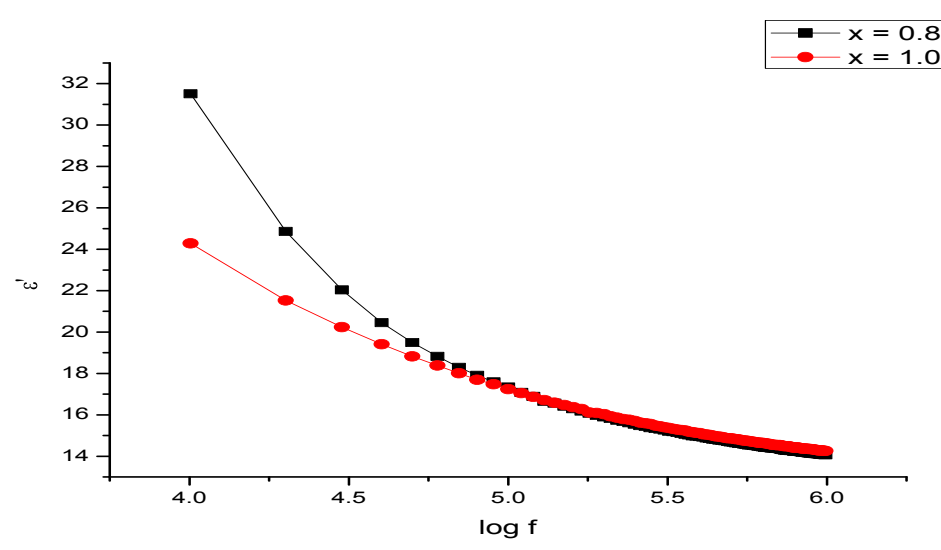

Figure4: Frequency dependence of $\dot{\varepsilon}$ for $\mathrm{Ca}(\mathrm{SnZr})_{x} \mathrm{Fe}_{12-x} \mathrm{O}_{19} ; \mathrm{x}=$ $0.8,1.0$ at $310 \mathrm{~K}$ 
According to Rabinkin and Novikova [17], the polarization in ferrites is through a mechanism similar to the conduction process. The polarization decreases with increase in frequency and then reaches a constant value due to the fact that beyond a certain frequency of external field, the electron exchange between $\mathrm{Fe}^{2+}$ and $\mathrm{Fe}^{3+}$ cannot follow the alternating field. The large value of $\dot{\varepsilon}$ at lower frequency is due to the predominance of species like $\mathrm{Fe}^{2+}$ ions, interfacial dislocations pile ups, oxygen vacancies, grain boundary defects, etc. [18], However the decrease in $\varepsilon$ with frequency is natural because of the fact that any species contributing to polarizability lag behind the applied field at higher and higher frequencies. Substitution of Sn-Zr content causes decrease in the number and the mobility of holes and hence results in a decrease in the values of both DC electrical resistivity and the dielectric constant up to this concentration. According to the Maxwell-Wagner model [19], the dielectric materials with heterogeneous structure can be imagined to contain well conducting grains separated by high resistive thin layers (grain boundaries). In this case, the applied voltage on the sample drops mainly across the grain boundaries and a space charge polarization is built up at the grain boundaries. The space charge polarization is governed by the available free charges on the grain boundary and the conductivity of the sample. Koops [20] proposed that the effect of grain boundaries is predominant at lower frequencies i.e. higher dielectric constant for thinner grain boundaries. High dielectric constants decrease the penetration depth of the electromagnetic waves by increasing the skin effect. Hence, the much lower dielectric constants obtained for the ferrites warrant their application at high frequencies.

\section{Conclusion}

Calcium hexaferrites doped with $\mathrm{Sn}^{2+}$ and $\mathrm{Zr}^{4+}$ ion, $\mathrm{Ca}(\mathrm{SnZ} \mathrm{Zr})_{\mathrm{x}} \mathrm{Fe}_{12-}$ ${ }_{2 \mathrm{x}} \mathrm{O}_{19}(\mathrm{x}=0.8$ and 1.0$)$ were prepared by the microwave induced sol-gel 
combustion technique. The X-ray diffraction studies confirm the formation of monophase M-type hexaferrites. The 'a' and 'c' values of the sample supports this confirmation. The conduction mechanism in calcium ferrite was explained on the basis of Verwey hopping model. The nanorange of particle size of hexaferrites helps to improve many magnetic parameters with the substitution of dopants ion for $\mathrm{Fe}^{3+}$ ions. The dc electrical resistivity of the samples decreases with increase in the temperature. The dielectric constant decrease with increasing frequency and are with agreement with dc electrical data.

\section{References}

A. Franco, and F.C. de Silva, (2010), Appl. Phys. Lett. 96172505

R. He, X. You, J. Shao, F. Gao, B. Pan, and D. Cui, (2007), Nanotechnol. 18315601 .

M. Veverka, P. Veverka, O. Kaman, A. Lančok, K. Závěta, E. Pollert, K. Knížek, J. Boháček, M. Beneš, P. Kašpar, E. Duguet, and S. Vasseur, (2007), Nanotechnol. 18 345704, 76.

R. Skomski, (2003), J. Phys.: Conden. Matter 15841.

Gorter E. W., (1957), Proc. IEEE 104B 255.

Komarneni S, D’ArrigoMC, Leonelli C, Pellacani G C and Katsuki H (1998) J. Am. Ceram. Soc. 813041.

Kreisel J, Vincent H, Taeest F, Pate M and Ganne J P, (2001), J. Magn. Magn. Mater. 22417.

Pankov V., (1997), Mater. Sci. Eng. A224 101.

Sable S N, Rewatkarb K G and Nanoti V M, ( 2009), Mater. Sci. Eng. B168 156.

Wang X, Li D, Lu L and Wang X, (1996), J. Alloys Compd. 23745.

Gawali. S.R, Moharkar. P. R., Sable. S.N., Nanoti. V. M., and K.G.Rewatkar. (2012), International Journal of Knowledge Engineering. vol 3. 
B. D. Cullity, (1976), "Elements of X-Ray Diffraction," Addi-son-Wesly Publishing, Boston.

M.J. Iqbal, M.N. Ashiq, P.H. Gomez, and J.M. Munoz, (2008), JMMM, 320, 383.

J.Smit, H.P.J. Wijn, Ferrites, and Wiley, (1959), New York.

E.J.W. Verwey and J.H. De Boer, (1936), Rec. Trans. Chem. Des. Pays. Bas. 55, 531.

S.W. Lee, S.Y. An, I. Shim and C.S. Kim., (2005), JMMM. 290-291, 231.

I.T. Rabinkin, Z.I. NovikovaFerrites and Izv Acad. (1960), Nauk USSR Minsk 146.

J.C. Maxwell, (1973), Electric and Magnetism, vol. 2, Oxford University Press, New York, 828.

K.W. Wagner, (1913), Ann. Phys. 40,817.

C. Koops, (1951), Phys. Rev. 83, 121. 